\title{
Changes over a workshift in aesthesiometric and vibrotactile perception thresholds of workers exposed to intermittent hand transmitted vibration from impact wrenches
}

\author{
Massimo Bovenzi, Piero Apostoli, Grazia Alessandro, Oscar Vanoni
}

\begin{abstract}
Objectives-To investigate the changes over a workshift in fingertip tactile perception thresholds in users of impact wrenches exposed to intermittent hand transmitted vibration. A further aim was to assess the relation between acute changes in tactile sensation, sensorineural disorders, and vibration dose.

Methods-The study populations consisted of 30 workers exposed to vibration (16 men and 14 women) and 25 control manual workers (10 men and 15 women). Sensorineural disorders in the fingers and hands were graded according to the staging system of the Stockholm workshop scale. Tactile function was tested by measuring aesthesiometric thresholds (two point discrimination and depth sense perception) and vibrotactile perception thresholds at $16,31.5$, and $125 \mathrm{~Hz}$ before and after a workshift. Temporary threshold shift was then calculated as the difference between threshold measures before and after the shift. The measurement and assessment of exposure to vibration were made according to the international standard ISO 5349. The vibration dose accumulated over a workshift $\left(\mathrm{m}^{2} \mathrm{~s}^{-4} \mathrm{~h}\right)$ was estimated for each user of impact wrenches. Daily exposure to vibration was also expressed in terms of eight hour energy equivalent frequency weighted acceleration $\left(\left(a_{h w}\right)_{e q(8)}\right.$ in $\left.\mathrm{ms}^{-2} \mathrm{rms}\right)$.
\end{abstract}

Results-After adjustment for age and alcohol consumption, vibrotactile perception thresholds before exposure were greater in the workers exposed to vibration than in the controls. No differences in aesthesiometric thresholds before the shift were found between the study groups. Sensorineural disorders were mild in the workers exposed to vibration and minor neurological abnormalities were detected at the physical examination. Owing to the intermittent use of impact wrenches, the estimated mean $\left(a_{h w}\right)_{e q(8)}$ for the subjects exposed to vibration was low (1.3 $\left.\mathrm{ms}^{-2} \mathrm{rms}\right)$. A significant temporary threshold shift in vibration perception at all test frequencies was found in the workers exposed to vibration but not in the controls. A significant increase in depth sense perception thresholds was found in the men exposed to vibration. The temporary threshold shift in vibration perception at $125 \mathrm{~Hz}$, and to a lesser extent at 16 and $31.5 \mathrm{~Hz}$, was associated with the severity of sensorineural disorders. In the workers exposed to vibration the temporary threshold shift in vibration sense at all test frequencies was positively related to the estimated dose of vibration received over a workshift. No significant relation was found between aesthesiometric threshold changes and vibration dose.

Conclusions-Intermittent exposure to hand transmitted vibration over a workshift can cause a deterioration of tactile perception in the fingers of users of impact wrenches. Acute tactile dysfunction was related to both the estimated dose of vibration and the severity of sensorineural symptoms. The temporary threshold shift in vibration perception suggested that fast adapting skin mechanoreceptors such as Pacinian and Meissner corpuscles were mainly involved in the acute sensory impairment to the fingertips of the workers exposed to vibration. Changes in tactile perception can occur in workers with daily exposure to vibration that is considered to be associated with a minimal risk of adverse health effects induced by vibration.

(Occup Environ Med 1997;54:577-587)

Keywords: acute tactile dysfunction, sensorineural disorders, vibration dose

Occupational exposure to vibration from hand held power tools is associated with an increased risk of neurological, vascular, and musculoskeletal disorders of the upper arms. ${ }^{12}$ These peripheral disorders are called hand-arm vibration syndrome. Early symptoms of the neurological component of the hand-arm vibration syndrome include intermittent or persistent tingling and numbness in the fingers and hands of the exposed workers. If exposure to vibration continues, these symptoms tend to worsen and can interfere with work capacity and life activities. Workers exposed to vibration may exhibit a reduction in the normal sense of touch, temperature, and pain as well as an impairment of manipulative dexterity at the physical examination. Another effect of hand 
transmitted vibration is a reduction of the sensitivity of the skin of the fingertips to vibration. It is thought that these findings are the clinical manifestations of a peripheral, diffusely distributed neuropathy with predominant sensory impairment. ${ }^{3}$

Vibration is sensed by various skin mechanoreceptors which are located in the epidermal, dermal, and subcutaneous tissues of the glabrous skin of the fingers and hands. ${ }^{4}$ Skin mechanoreceptors are innervated by A- $\alpha$ myelinated fibres and are classified into four types according to their adaptation to stimuli and the characteristics of their receptive fields. ${ }^{56}$ Fast adapting (FAI and FAII) receptors respond to skin motion, whereas slow adapting (SAI and SAII) receptors are activated during indentation and constant deformation of the skin. The receptive fields of type $I$ units are small with distinct edgings, whereas those of type II units are larger with indeterminate borders. The end organs of FAI units are probably Meissner's corpuscles which respond to frequencies between 5 and $50 \mathrm{~Hz}$. The Pacinian corpuscles (and possibly Golgi-Mazzoni bodies) belong to FAII units which are sensitive at frequencies above $50 \mathrm{~Hz}$. The SA units include Merkel's cell neurite complexes (SAI) and Ruffini endings (SAII) that are sensitive at frequencies lower than 8-16 Hz. Experimental studies have shown that intense hand transmitted vibration can affect the integrity or functional capacity of skin mechanoreceptors, even in subjects with normal tactile sensitivity. ${ }^{7}$ This may explain the symptoms of digital paraesthesias and numbness reported by professional users of vibrating tools as well as the signs of impaired tactile sensation and loss of precise manipulation exhibited by these patients at the neurological examination.

An increase in vibrotactile perception thresholds of the fingertips has often been found in the early stages of the hand-arm vibration syndrome. ${ }^{4}$ At the 1994 Stockholm workshop on the diagnostic and quantitative relations to exposure in hand-arm vibration syndrome, the experts of the working group on vibration induced sensorineural disturbances recommended the measurement of vibrotactile thresholds as a screening test for detecting an incipient neurological injury. ${ }^{8}$ To assess the function of different mechanoreceptor populations, multifrequency vibrotactile thresholds should be measured on the tips of fingers innervated by the median and ulnar nerves. Other psychophysical measures such as aesthesiometric thresholds were considered suitable to disclose more advanced stages of vibration induced neuropathy. Aesthesiometric and vibrotactile sense threshold testing has been used in laboratory investigations to detect the acute effects of controlled vibration stimuli on tactile perception as well as in clinical and epidemiological studies to measure the severity of sensory disorders in workers occupationally exposed to hand transmitted vibration. ${ }^{9-20}$ There is a shortage of data on the acute changes in tactile sense caused by exposure to vibration in the workplace under actual operating conditions. Haines et al investigated vibra- tion induced changes in neurological function over the course of a workshift in hard rock miners, but their study was restricted to aesthesiometric thresholds. ${ }^{21}$ The main purpose of the present study was to investigate whether intermittent exposure to hand transmitted vibration over a workshift can induce acute changes in aesthesiometric and vibrotactile perception thresholds in the fingertips of users of impact wrenches. A further aim of this field study was to assess the relation between acute changes in tactile sensation, symptoms of sensorineural disorders, and the vibration dose accumulated over a workshift.

\section{Methods}

SUBJECTS AND MEDICAL INVESTIGATIONS

The study population consisted of all 30 workers exposed to vibration (16 men and 14 women) employed in the production and assembly workshops of a large factory producing plastic articles. The workers used two different models of impact wrenches from the same manufacturer to tighten screws, bolts, and nuts on the surface of metal frames and moulds. The control group consisted of 25 manual workers ( 10 men and 15 women) who had never used vibrating tools. They were engaged mainly in maintenance activities.

Each worker attended a medical interview and a complete physical examination. The subjects were carefully questioned about smoking and drinking habits, cardiovascular, neurological, and metabolic diseases, previous musculoskeletal injuries, and use of medicines. None reported a medical history of diabetes, rheumatoid arthritis, thyroid gland disorders, or generalised neuropathies. Occupational history showed that no worker had been exposed to industrial neurotoxic agents in the past. No subject was affected with abnormalities of the fingers such as post-traumatic injuries or fingertip calluses. On the basis of the results of the medical interview and a clinical neurological examination, peripheral sensorineural disorders in the fingers and hands were staged according to a scale similar to that proposed by Brammer et al: $0=$ no sensorineural symptoms; $1=$ intermittent numbness, with or without tingling; $2=$ intermittent or persistent numbness and reduced sensory perception assessed by traditional neurological tests (light touch, temperature, and pain); $3=$ persistent numbness, reduced sensory perception, and impaired manipulative dexterity. ${ }^{22}$ Symptoms of persistent discomfort, ache, or pain in the hand-arm system during the previous 12 months were also investigated. Carpal tunnel syndrome (CTS) was suspected if typical symptoms and signs were present - that is, pain, numbness or tingling in the median nerve distribution of the hand, nocturnal exacerbation, positive Tinel's sign at the carpal tunnel or positive Phalen's wrist flexion test, diminished sensitivity to touch or pain in three and a half fingers on the radial side of the hand. 
AESTHESIOMETRIC AND VIBROTACTILE TESTING PROCEDURE

Aesthesiometric (two point discrimination and depth sense perception) and vibrotactile sense thresholds were measured in both hands of the workers exposed to vibration and the controls at the start of a workshift. In the users of impact wrenches assessment of tactile function before the shift was conducted after at least 16 hours from the last exposure to hand transmitted vibration. Aesthesiometric measures were taken on the distal pads of the second and fifth fingers of both hands, and vibrotactile perception thresholds were determined on the distal pads of the second, third, and fifth fingers of both hands. Measurements of tactile perception thresholds after the shift were made only in the fingers of the dominant hand within five minutes of the end of the workshift. The duration of a typical workshift was six hours. Measurements before and after the shift were performed in a soundproof and thermoregulated room. Ambient temperature averaged 22 (SD 0.2$)^{\circ} \mathrm{C}$. Finger skin temperatures greater than $25^{\circ} \mathrm{C}$ were required before the start of the testing procedures. ${ }^{17}$ There were no significant differences in finger skin temperature before and after the shift either within or between each study group.

Two point discrimination and depth sense perception thresholds were obtained with two aesthesiometers as developed by Carlson et al. ${ }^{23}$ A tunnel shaped instrument was also used to maintain a constant finger pressure and position on the aesthesiometers. Briefly, the two point discrimination aesthesiometer has a surface containing a $5 \mathrm{~mm}$ deep double edged groove of progressively increasing width which can test fingertip gap detection thresholds between 0 and $6 \mathrm{~mm}$. The depth sense perception aesthesiometer has a surface containing a step of continuously varying height which can detect fingertip depth sense thresholds from 0 to $1.5 \mathrm{~mm}$. A complete description of the apparatus and testing methods have been reported elsewhere. ${ }^{24}$ On each testing occasion three measurements of fingertip two point discrimination and depth sense perception were made and the mean value was taken as the threshold for gap detection and depth sensation, respectively.

Vibrotactile perception thresholds were measured at the frequencies of $16,31.5$, and $125 \mathrm{~Hz}$ with the HVLab tactile vibrometer developed at the University of Southampton's Institute of Sound and Vibration Research. ${ }^{25}$ The apparatus consists of an electrodynamic vibrator which drives a $6 \mathrm{~mm}$ diameter probe protruding through a circular hole of $10 \mathrm{~mm}$ diameter in a strain gauged perspex surround.
The probe has a counter balance providing a constant upward force of $1 \mathrm{~N}$. The vibrometer was interfaced with a personal computer. The subject was asked to place the distal pad of the test finger over the vibrometer probe and push down with a force of $2 \mathrm{~N}$, feedback being provided by a force meter. A computer controlled and measured the sinusoidal vibration stimulus. During vibrotactile testing, the subject was instructed to press a response button as soon as he or she felt the vibration, to keep the button down until the vibration disappeared and then to release it. The process was repeated several times to obtain a vibrogram consisting of sequences of increasing and decreasing levels of vibration with different frequencies. Six consistent vibration reversals were recorded at each test frequency. The procedure is similar to that used in automatic audiometry (von Békésy method). The set of frequencies chosen for this study was automatically presented to the subject in an ascending order. The software computed the mean vibrotactile perception threshold at each frequency by averaging the peaks and troughs of the acceleration time history of the vibrating probe according to the procedures defined in the British standard BS 6655 and the international standard ISO $6189 .{ }^{26}{ }^{27}$ For the purpose of this study, vibrotactile perception thresholds were expressed in decibels $(\mathrm{dB})$ relative to a reference root mean squared (rms) acceleration of $10^{-6}$ $\mathrm{ms}^{-2}$. The vibrograms and statistical reports were displayed on the computer screen and output to a printer. During testing the subject sat on a chair with the forearm and hand supported by the vibrometer box.

Before testing each subject underwent a period of familiarisation with the instruments for both aesthesiometry and vibrometry to understand the testing procedure and to avoid learning effects. During the testing session, aesthesiometric thresholds were measured before vibrotactile thresholds both at the beginning and the end of the workshift.

\section{MEASUREMENT AND ASSESSMENT OF VIBRATION} EXPOSURE

Table 1 shows the characteristics of the two impact wrenches used in the factory. Vibration was measured on the pistol control handle of the impact wrenches during actual operation according to the recommendations of the international standards ISO 5349 and ISO $8662-1 .^{28}{ }^{29}$ Overall the measuring procedure consisted of 174 test runs. The time for each test run was about 4-5 s. One third octave band frequency spectra $(6.3-1250 \mathrm{~Hz})$ in the orthogonal directions $x, y$, and $z$ were obtained by a real time analyser (Larson and Davis

Table 1 Mean (SD) values of the frequency weighted root mean square $(r m s)$ acceleration of vibration ( $a_{m}$ ) measured in three orthogonal directions $(x, y, z)$ on the pistol control handle of the impact wrenches used by the workers exposed to vibration

\begin{tabular}{|c|c|c|c|c|c|c|c|c|}
\hline \multirow[b]{2}{*}{ Tool type } & \multirow[b]{2}{*}{ Mass (kg) } & \multirow{2}{*}{$\begin{array}{l}\text { Pressure } \\
(\mathrm{kPa})\end{array}$} & \multirow{2}{*}{$\begin{array}{l}\text { Rotational } \\
\text { speed (rpm) }\end{array}$} & \multirow{2}{*}{$\begin{array}{l}\text { Test runs } \\
(n)\end{array}$} & \multicolumn{4}{|c|}{ Frequency weighted acceleration ( $\mathrm{ms}^{-2} \mathrm{rms}$ ) } \\
\hline & & & & & $a_{\text {heux }}$ & $a_{h a y}$ & $a_{h u z}$ & $a_{\text {heos }}$ \\
\hline $\begin{array}{l}\text { IR } 231 \\
\text { IR } 261\end{array}$ & $\begin{array}{l}2.6 \\
5.3\end{array}$ & $\begin{array}{l}620 \\
620\end{array}$ & $\begin{array}{l}7000 \\
5500\end{array}$ & $\begin{array}{l}98 \\
76\end{array}$ & $\begin{array}{l}1.13(0.37) \\
2.92(0.40)\end{array}$ & $\begin{array}{l}1.14(0.40) \\
2.90(0.32)\end{array}$ & $\begin{array}{l}3.76(0.90) \\
5.71(0.84)\end{array}$ & $\begin{array}{l}4.19(0.76) \\
7.12(0.73)\end{array}$ \\
\hline
\end{tabular}

$a_{h w s}=$ frequency weighted rms acceleration sum, $\left(a_{\text {hwx }}^{2}+a_{b w y}^{2}+a_{b w z}^{2}\right)^{1 / 2}$. 

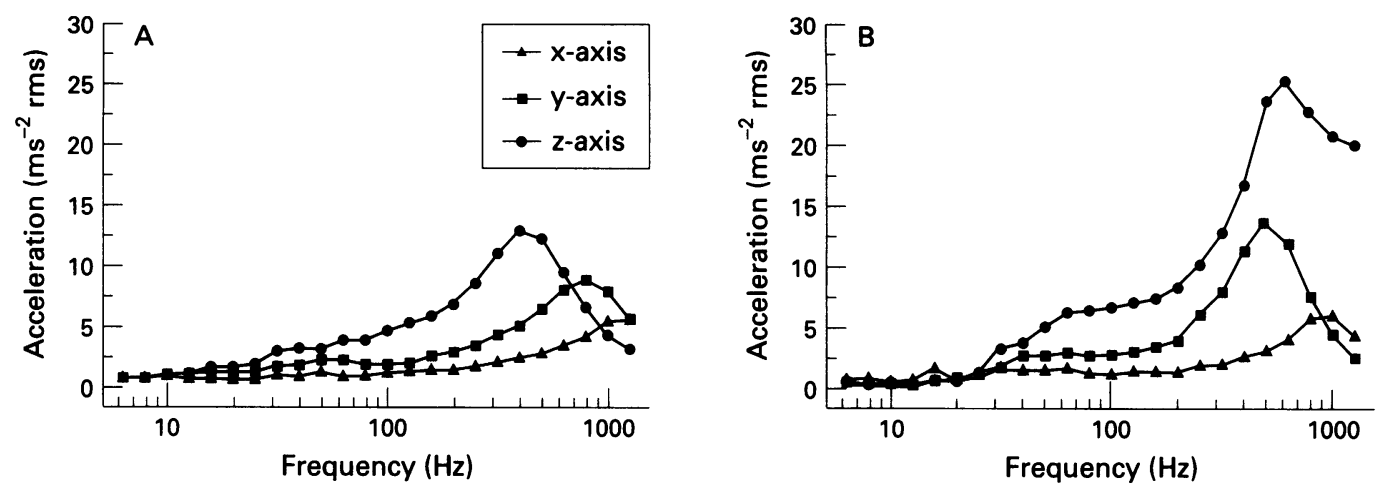

Figure 1 One third octave band frequency spectra $(6.3-1250 \mathrm{~Hz})$ recorded on the pistol control handle of the two impact wrenches used by the workers exposed to vibration.

2900). The results of the one third octave band analysis (fig 1) were used to estimate the corresponding magnitude of the frequency weighted rms acceleration $\left(a_{h w}\right)$ according to ISO $5349 .{ }^{28}$ The frequency weighted rms acceleration sum $\left(a_{\text {hws }}\right)$ was calculated from the following formula:

$$
a_{h w s}=\left(a_{h w x}^{2}+a_{h w y}^{2}+a_{h w z}^{2}\right)^{1 / 2} \mathrm{~ms}^{-2} \text { rms. }
$$

The mean values of $a_{\text {hws }}$ estimated for the two impact wrenches were 4.2 and $7.1 \mathrm{~ms}^{-2} \mathrm{rms}$, respectively (table 1 ). These figures are consistent with those reported in other studies of vibration generated by impact wrenches during the tightening of nuts. ${ }^{30}$ Direct observations of the operating conditions in the workplace showed that the impact wrenches were used repeatedly over a workshift (40-160 fastenings/ h). The duration of each wrenching operation was very short (3-6 s) resulting in an intermittent exposure to hand transmitted vibration. The daily exposure time of each worker exposed to vibration was monitored over the course of the working day during which aesthesiometric and vibrotactile testing was carried out. Assuming a fastening operation as the basic work cycle, the individual exposure time to hand transmitted vibration was estimated as the mean duration of the work cycle multiplied by the number of work cycles per day. According to this procedure, the time the operator had the hand in contact with the vibrating tool averaged $1.16 \mathrm{~h} /$ day for the male workers and $0.30 \mathrm{~h} /$ day for the female workers. Daily exposure to vibration was then assessed in terms of eight hour energy equivalent frequency weighted acceleration $\left(\left(a_{h w}\right)_{e q(8)}\right.$ in $\mathrm{ms}^{-2} \mathrm{rms}$ ) according to the British standard 6842:

$$
\left(a_{h w}\right)_{e q(8)}=(T / 8)^{1 / 2}\left(a_{h w}\right)_{e q(T)} \mathrm{ms}^{-2} \mathrm{rms}
$$

where $\left(a_{h w}\right)_{e q(T)}$ is the frequency weighted energy equivalent acceleration for a daily exposure of $T$ hours. ${ }^{31}$

The vibration dose accumulated by each worker at the time of testing was also estimated as:

Vibration dose $=\left(\left(a_{\text {hus }}\right)^{2} t_{h}\right) \mathrm{m}^{2} \mathrm{~s}^{-4} \mathrm{~h}$

where $\left(a_{h w s}\right)$ is the frequency weighted rms acceleration sum measured on the handle of the impact wrench used by each worker and $t_{h}$ was the individual daily exposure period (hours) estimated at the time of testing.

\section{DATA ANALYSIS}

The change over a workshift in aesthesiometric $(\mathrm{mm})$ and vibrotactile $(\mathrm{dB})$ thresholds was calculated as the difference between measurements before and after the shift, an outcome that is commonly called temporary threshold shift. Data were summarised with mean as a measure of central tendency and SD or SEM as measures of dispersion. The difference between two means was tested by unpaired or paired Student's $t$ test, when appropriate. To adjust for the influence of confounding variables such as age and alcohol consumption, one way analysis of covariance (ANCOVA) was used to test the equality of the adjusted means of independent samples. Repeated measures ANCOVA was used when adjustment for covariates was applied to paired samples. The relation between continuous variables was assessed by simple or multivariate regression analysis. The strength of the association between two variables was measured by either the Pearson product moment correlation coefficient or the Spearman rank correlation coefficient. The difference between categorical variables tabulated in $2 \times 2$ or $2 \times k$ contingency tables was tested by either Fisher's exact test or the $\chi^{2}$ statistic. A P value of 0.05 was chosen as the limit of significance. Data analysis was performed by the BMDP/dynamic software (release 7.0). The statistical package StatXact (version 2.12) was used for exact non-parametric inference.

\section{Results}

Table 2 reports the characteristics of the study populations. Among the female workers those exposed to hand transmitted vibration were younger than the controls $(P<0.05)$, whereas no difference in age was found between the two male subgroups. Anthropometric variables and smoking habits were comparable between the workers exposed to vibration and the respective controls in both the male and female groups. In the men alcohol consumption was greater in the workers exposed to vibration than in the controls $(P<0.01)$. Vibration exposure expressed in terms of daily exposure time $\left(a_{h w}\right)_{e q(8)}$ and vibration dose was found to be higher in the men than in the women $(P<0.01)$. In the whole group exposed to vibration the mean (SD) estimated $\left(a_{h w}\right)_{e q(8)}$ was $1.33(0.31) \mathrm{ms}^{-2}$ 
Table 2 Characteristics of the worker exposed to vibration and the controls with the men and women both separately and combined

\begin{tabular}{|c|c|c|c|c|c|c|c|c|c|c|c|c|}
\hline \multirow{4}{*}{ Age (y, mean (SD)) } & \multicolumn{4}{|c|}{ Male workers } & \multicolumn{4}{|c|}{ Female workers } & \multicolumn{4}{|l|}{ Total } \\
\hline & \multicolumn{2}{|c|}{ Exposed $(n=16)$} & \multicolumn{2}{|c|}{ Controls $(n=10)$} & \multicolumn{2}{|c|}{ Exposed $(n=14)$} & \multicolumn{2}{|c|}{ Controls $(n=15)$} & \multicolumn{2}{|c|}{ Exposed $(n=30)$} & \multicolumn{2}{|c|}{ Controls $(n=25)$} \\
\hline & 34.5 & $(9.4)$ & 30. & $(5.7)$ & 27.6 & $(4.2)$ & 32.3 & $(7.4)^{\star}$ & 31.3 & $(8.1)$ & 31. & $(6.7)$ \\
\hline & 170 & $(4.4)$ & 172 & $(6.1)$ & 164 & $(2.5)$ & 163 & $(8.5)$ & 166 & $(4.9)$ & 166 & $(7.5)$ \\
\hline Weight (kg, mean (SD)) & 69.0 & $(6.5)$ & 70. & $(7.6)$ & 59.0 & $(8.2)$ & 56.5 & $(7.7)$ & 64.6 & $(8.5)$ & 62. & $(10.3)$ \\
\hline Body mass index $\left(\mathrm{kg} / \mathrm{m}^{2}\right.$, mean $\left.(\mathrm{SD})\right)$ & 24.2 & $(1.8)$ & 23. & (1.8) & 22.2 & (2.5) & 21.5 & $(3.1)$ & 23.2 & $(2.4)$ & 22. & $(2.9)$ \\
\hline \multicolumn{13}{|l|}{ Cigarette smoking (n (\%)): } \\
\hline Never & 6 & $(37.5)$ & 3 & $(30.0)$ & 8 & $(57.1)$ & 10 & $(66.7)$ & 14 & $(46.7)$ & 13 & $(52.0)$ \\
\hline Ex-smokers & 2 & (12.5) & 1 & $(10.0)$ & 1 & $(7.1)$ & 2 & (13.3) & 3 & $(10.0)$ & 3 & $(12.0)$ \\
\hline Current smokers & 8 & $(50.0)$ & 6 & $(60.0)$ & 5 & (35.7) & 3 & $(20.0)$ & 13 & (43.3) & 9 & $(36.0)$ \\
\hline \multicolumn{13}{|l|}{ Alcohol $(\mathrm{g} / \mathrm{d}, \mathrm{n}(\%))$ : } \\
\hline 0 & 2 & $(12.5)$ & 4 & $(40.0)$ & 11 & (78.6) & 14 & $(93.3)$ & 13 & $(43.3)$ & 18 & $(72.0)$ \\
\hline$<50$ & 1 & $(6.2)$ & 4 & $(40.0)$ & 3 & (21.4) & 1 & $(6.7)$ & 4 & (13.3) & 5 & $(20.0)$ \\
\hline$>\mathbf{5 0}$ & 13 & $(81.2)$ & 2 & $(20.0) \ddagger$ & 0 & (0) & 0 & $(0)$ & 13 & (43.3) & 2 & $(8.0) \dagger$ \\
\hline Vibration exposure time (h/day, mean (SD)) & 1.16 & $(0.41)$ & - & & 0.30 & $(0.15)^{\star \star}$ & - & & 0.7 & $(0.54)$ & - & \\
\hline$\left(a_{\mathrm{hw}}\right)_{\mathrm{eq}(8)}\left(\mathrm{ms}^{-2} \mathrm{rms}\right.$, mean (SD)) & 1.45 & $(0.27)$ & - & & 1.19 & $(0.31)^{\star \star}$ & - & & 1.3 & $(0.31)$ & - & \\
\hline Vibration dose $\left(\mathrm{m}^{2} \mathrm{~s}^{-4} \mathrm{~h}\right.$, mean (SD)) & 17.4 & $(6.2)$ & - & & 12.1 & $(6.1)^{\star \star}$ & - & & 14.9 & $(6.6)$ & - & \\
\hline
\end{tabular}

$\left(a_{\text {hw }}\right)_{\text {eq(8) }}=$ eight hour energy equivalent value of the frequency weighted acceleration sum.

$\star \mathrm{P}<0.05 ; \star \star \mathrm{P}<0.01, t$ test.

$\dagger \mathrm{P}<0.02 ; \ddagger \mathrm{P}<0.01, \chi^{2}$ test.

Table 3 Disorders in the fingers, hands, and wrists of the workers exposed to vibration and the controls (sensorineural symptoms were staged according to the Stockholm workshop scale)

\begin{tabular}{|c|c|c|c|c|c|c|}
\hline & \multicolumn{2}{|l|}{ Male workers } & \multicolumn{2}{|l|}{ Female workers } & \multicolumn{2}{|l|}{ Total } \\
\hline & Exposed $(n=16)$ & Controls $(n=10)$ & Exposed $(n=14)$ & Controls $(n=15)$ & Exposed $(n=30)$ & Controls $(n=25)$ \\
\hline \multicolumn{7}{|l|}{ Sensorineural stages: } \\
\hline OSN & $6(37.5)$ & $9(90.0)$ & $10(71.4)$ & $12(80.0)$ & $16(53.3)$ & $21(84.0)$ \\
\hline $1 \mathrm{SN}$ & $9(56.2)$ & $1(10.0)$ & $1(7.1)$ & $1(6.7)$ & $10(33.3)$ & $2(8.0)$ \\
\hline $2 \mathrm{SN}$ & $0(0)$ & $0(0)$ & $1(7.1)$ & $1(6.7)$ & $1(3.3)$ & $1(4.0)$ \\
\hline $3 \mathrm{SN}$ & $1(6.2)$ & $0(0)+$ & $2(14.3)$ & $1(6.7)$ & $3(10.0)$ & $1(4.0)$ \\
\hline Hand-wrist pain in the past 12 months & $12(75.0)$ & $3(30.0)^{\star}$ & $11(78.6)$ & $6(40.0)^{\star}$ & $23(76.7)$ & $9(36.0)^{\star \star}$ \\
\hline Signs and symptoms of CTS & $1(6.2)$ & $0(0)$ & $3(21.4)$ & $2(13.3)$ & $4(13.3)$ & $2(8.0)$ \\
\hline
\end{tabular}

$\star \mathrm{P}<0.05 ;{ }^{\star \star} \mathrm{P}<0.01, \chi^{2}$ test.

$+P<0.03$, exact $\chi^{2}$ test. Values are $n(\%)$.

rms. Previous regular use of vibrating tools other than impact wrenches was reported by two workers exposed to vibration (one man and one woman). The duration of exposure to hand transmitted vibration averaged 1.9 years in the men and 2.9 years in the women ( $t$ test: $\mathrm{P}=0.13$ ).

DISORDERS OF THE FINGERS, HANDS, AND WRISTS The overall prevalence of sensorineural disturbances in the fingers and hands was $46.7 \%$ among the workers exposed to vibration and $16.0 \%$ among the controls $(P<0.02)$. Sensorineural disorders were more severe in the workers exposed to vibration than in the controls (table 3), but the difference in the distribution of sensorineural stages was significant only for the male group $(P<0.03)$. Univariate analysis showed that in the men exposed to vibration sensorineural symptoms were associated with age, alcohol consumption, and vibration dose $(\mathrm{P}<0.05)$. A clinical picture suggestive of CTS was found in four workers exposed to vibration and two controls $(P=0.68)$. Electrodiagnostic tests (sensory and motor nerve conduction) confirmed the presence of CTS in four women (two exposed to vibration and two controls). No significant association was found between exposure to vibration and symptoms and signs of CTS at the clinical examination. The prevalence of persistent pain in the hands and wrists was significantly greater in the workers exposed to vibration than in the controls for both the men and the women $(\mathrm{P}<0.05)$. Vibration induced white finger (VWF) was reported by one man $(3.3 \%$ of the total sample). This worker had had previous experience with vibrating tools and had been compensated for VWF.

TACTILE PERCEPTION BEFORE THE WORKSHIFT Aesthesiometric (two point discrimination and depth sense perception) thresholds at the start of the workshift were not different between the workers exposed to vibration and the controls in either the men or the women. Also within each of these four subgroups there was no difference between the dominant and nondominant hands (results not shown).

After adjustment for age and alcohol consumption, vibrotactile perception thresholds at the frequencies of $16,31.5$, and $125 \mathrm{~Hz}$ were significantly greater in the men exposed to vibration than the respective controls for most of the test fingers of both the dominant and the non-dominant hand (table 4). In the female group vibrotactile perception thresholds were higher in the workers exposed to vibration than in the controls, but the difference was significant only in the second finger of the dominant hand for $125 \mathrm{~Hz}$ and in the fifth finger of the same hand for $31.5 \mathrm{~Hz}$. Within each subgroup there was no difference in vibrotactile perception thresholds at the various frequencies between the dominant and the non-dominant hand. In the control groups vibrotactile perception thresholds at all test frequencies were significantly correlated with age $(0.001<\mathrm{P}<0.05)$. No difference in two point discrimination, depth sense perception, and vibrotactile perception thresholds of the fingertips of both 
Table 4 Measures before the shift of vibration perception thresholds at the frequencies of 16, 31.5, and $125 \mathrm{~Hz}$ for the second, third, and fifth fingers of both hands of the exposed workers and the controls

\begin{tabular}{|c|c|c|c|c|c|}
\hline \multirow[b]{2}{*}{ Test side } & \multirow[b]{2}{*}{ Frequency $(\mathrm{Hz})$} & \multicolumn{4}{|c|}{ Vibration perception thresholds $(d B)$} \\
\hline & & $\begin{array}{l}\text { Male workers } \\
\text { Exposed }(n=16)\end{array}$ & Controls $(n=10)$ & $\begin{array}{l}\text { Female workers } \\
\text { Exposed }(n=14)\end{array}$ & Controls $(n=15)$ \\
\hline \multicolumn{6}{|c|}{ Dominant hand: } \\
\hline \multirow{3}{*}{ Finger II } & 16 & $103.1(12.2)$ & $93.6(4.5)^{\star}$ & $100.4(9.9)$ & $96.6(6.0)$ \\
\hline & 31.5 & $106.9(7.4)$ & $100.9(3.7)^{\star}$ & $105.9(10.2)$ & $102.6(6.4)$ \\
\hline & 125 & $108.9(6.7)$ & $107.1(4.9)$ & $114.0(8.6)$ & $108.3(5.9)^{\star}$ \\
\hline \multirow[t]{3}{*}{ Finger III } & 16 & $99.6(4.8)$ & $93.1(4.4)^{\star \star}$ & $99.9(10.9)$ & $95.4(8.1)$ \\
\hline & 31.5 & $108.3(5.5)$ & $101.9(3.6)^{\star \star}$ & $106.2(10.0)$ & $105.2(9.0)$ \\
\hline & 125 & $112.5(5.4)$ & $107.4(5.6)^{\star}$ & $114.0(9.7)$ & $108.8(8.9)$ \\
\hline \multirow{3}{*}{ Finger $\mathrm{V}$} & 16 & $100.6(5.9)$ & $94.4(6.9)^{\star}$ & $102.7(10.5)$ & $96.7(7.4)$ \\
\hline & 31.5 & $109.9(6.1)$ & $102.2(4.4)^{\star \star}$ & $109.8(11.1)$ & $102.5(6.7)^{\star}$ \\
\hline & 125 & $112.5(8.0)$ & $109.1(6.0)$ & $117.4(9.6)$ & $110.7(8.1)$ \\
\hline \multicolumn{6}{|c|}{ Non-dominant hand: } \\
\hline \multirow[t]{3}{*}{ Finger II } & 16 & $101.3(5.5)$ & $94.3(4.8)^{\star \star}$ & $96.6(7.3)$ & $96.0(4.9)$ \\
\hline & 31.5 & $108.6(5.3)$ & $101.7(6.1)^{\star \star}$ & $103.1(7.9)$ & $103.4(5.8)$ \\
\hline & 125 & $110.6(8.2)$ & $105.9(6.2)$ & $110.4(9.2)$ & $108.0(6.8)$ \\
\hline \multirow[t]{3}{*}{ Finger III } & 16 & $103.1(4.9)$ & $96.6(5.2)^{\star \star}$ & $98.1(9.1)$ & $96.1(6.3)$ \\
\hline & 31.5 & $109.9(4.8)$ & $102.8(6.7)^{\star \star}$ & $105.6(8.2)$ & $103.6(6.2)$ \\
\hline & 125 & $113.6(8.8)$ & $106.8(5.4)^{\star}$ & $111.9(8.3)$ & $108.9(7.5)$ \\
\hline \multirow[t]{3}{*}{ Finger $\mathrm{V}$} & 16 & $103.9(7.9)$ & $96.7(5.1)^{\star}$ & $100.0(7.0)$ & $96.6(6.5)$ \\
\hline & 31.5 & $111.1(6.6)$ & $104.3(6.8)^{\star \star}$ & $106.3(8.6)$ & $103.5(5.6)$ \\
\hline & 125 & $116.4(9.5)$ & $109.7(5.1)^{\star}$ & $111.9(9.7)$ & $110.4(7.7)$ \\
\hline
\end{tabular}

Values are means (SD) and expressed in decibels (dB) relative to $10^{-6} \mathrm{~ms}^{-2} \mathrm{rms}$.

$\star \mathrm{P}<0.05 ;{ }^{\star \star} \mathrm{P}<0.01$, analysis of covariance (covariates: age and alcohol consumption).

hands was found between the male and female controls.

\section{CHANGES OVER A WORKSHIFT IN TACTILE PERCEPTION}

No significant changes over a workshift in two point discrimination thresholds were found either within or between groups (table 5). When the men and women exposed to vibration were combined together, there was a marginally significant increase in two point discrimination thresholds for the fifth finger. Depth sense perception thresholds significantly increased in the men exposed to vibration but not in the respective controls as did the depth sense perception thresholds of the fifth finger. In the female group there was no difference in the changes of depth sense perception thresholds either within the workers exposed to vibration and the controls or between them.

No significant changes over a workshift in vibrotactile perception thresholds at $16,31.5$, and $125 \mathrm{~Hz}$ were found in either the male and the female controls (table 6). The men exposed to vibration showed a significant temporary threshold shift in vibration perception at 16 and $31.5 \mathrm{~Hz}$ for the third and fifth fingers, and at $125 \mathrm{~Hz}$ for the second and fifth fingers. The temporary threshold shift at 16 and $125 \mathrm{~Hz}$ differed significantly from that found in the male controls for the third and fifth fingers, respectively. The women exposed to vibration had a significant temporary threshold shift at $31.5 \mathrm{~Hz}$ for the third finger as well as at $125 \mathrm{~Hz}$ for all of the three fingers tested. The temporary threshold shift at $125 \mathrm{~Hz}$ for the second and third fingers was significantly higher than that measured in the female controls. Similar results were obtained when either the cases of CTS confirmed by electroneurography or the subjects with previous exposure to hand transmitted vibration were excluded from data analysis.

In the workers exposed to vibration the changes over a workshift in two point discrimination, depth sense perception, and vibrotactile perception thresholds at all test frequencies were inversely related to the respective absolute thresholds obtained at the start of the workshift $(P<0.05)$. In contrast, such relations were not found in the controls.

When the workers exposed to vibration were divided into the various stages of sensorineural disorders (fig 2), after adjustment for age, sex, and alcohol consumption, the changes over a workshift in fingertip vibrotactile perception thresholds at the frequency of $125 \mathrm{~Hz}$ were significantly greater in the subjects with more severe sensorineural symptoms $(2+3)$ than in the controls and the other exposed workers with mild disturbances (1) or with no symptoms (0). The same trend was found for the frequencies of 16 and $31.5 \mathrm{~Hz}$ but the differences were marginally significant and

Table 5 Changes over a workshift in two point discrimination and depth sense perception for the second and fifth fingers of the dominant hand of the exposed workers and the controls

\begin{tabular}{|c|c|c|c|c|c|c|}
\hline \multirow[b]{2}{*}{ Finger } & \multicolumn{2}{|l|}{ Male workers } & \multicolumn{2}{|l|}{ Female workers } & \multicolumn{2}{|l|}{ Total } \\
\hline & Exposed $(n=16)$ & Controls $(n=10)$ & Exposed $(n=14)$ & Controls $(n=15)$ & Exposed $(n=30)$ & Controls $(n=25)$ \\
\hline \multicolumn{7}{|c|}{ Two point discrimination ( $\mathrm{mm}$ ): } \\
\hline II & $(0.13)$ & $0.04 \quad(0.09)$ & $0.06(0.12)$ & $0.20(0.09)$ & $(0.09)$ & $0.10(0.07)$ \\
\hline V & $(0.09)$ & $-0.08(0.10)$ & $0.10(0.06)$ & $0.12(0.09)$ & $0.14^{\star} \quad(0.05)$ & $0.04(0.07)$ \\
\hline \multicolumn{7}{|c|}{ Depth sense perception (mm): } \\
\hline II & $0.09^{\star \star}(0.03)$ & $0.01 \quad(0.03)$ & $0.04(0.03)$ & $0.06(0.03)$ & $0.07^{\star \star \star}(0.02)$ & $0.04(0.02)$ \\
\hline $\bar{V}$ & $0.10^{\star \star \star}(0.02)$ & $0.01+(0.03)$ & $0.05(0.03)$ & $0.05(0.03)$ & $0.07^{\star \star \star}(0.02)$ & $0.03(0.03)$ \\
\hline
\end{tabular}

Values are mean differences (SEM) between measures of thresholds $(\mathrm{mm})$, before and after the shift.

Paired samples: ${ }^{\star} P<0.05,{ }^{\star \star} P<0.02,{ }^{\star \star \star} P<0.01$; independent samples: $+P<0.05$, analysis of covariance (covariates: age and alcohol consumption). 
Table 6 Changes over a workshift in vibrotactile perception thresholds at the frequencies of 16, 31.5, and $125 \mathrm{~Hz}$ for the second, third, and fifth fingers of the dominant hand of the exposed workers and the controls

\begin{tabular}{|c|c|c|c|c|c|c|c|c|c|c|c|}
\hline \multirow[b]{2}{*}{$\begin{array}{l}\text { Frequency } \\
(\mathrm{Hz})\end{array}$} & \multirow[b]{2}{*}{ Finger } & \multicolumn{3}{|l|}{ Male workers } & \multicolumn{4}{|c|}{ Female workers } & \multicolumn{3}{|l|}{ Total } \\
\hline & & $\begin{array}{l}\text { Exposed } \\
(n=16)\end{array}$ & $\begin{array}{l}\text { Controls } \\
(n=10)\end{array}$ & $\begin{array}{l}P \\
\text { valuest }\end{array}$ & $\begin{array}{l}\text { Exposed } \\
(n=14)\end{array}$ & & $\begin{array}{l}\text { Controls } \\
(n=15)\end{array}$ & $\begin{array}{l}P \\
\text { valuest }\end{array}$ & $\begin{array}{l}\text { Exposed } \\
(n=30)\end{array}$ & $\begin{array}{l}\text { Controls } \\
(n=25)\end{array}$ & $\begin{array}{l}P \\
\text { valuest }\end{array}$ \\
\hline \multirow[t]{3}{*}{16} & II & (3.47) & $0.24(1.05)$ & NS & 0.51 & $(1.09)$ & $0.40(1.19)$ & NS & $(1.42)$ & $0.33(1.10)$ & NS \\
\hline & III & $5.94^{\star \star \star}(1.89)$ & $0.36(1.00)$ & $<0.03$ & 2.74 & (1.89) & $3.03(1.73)$ & NS & $4.46^{\star \star \star}(1.35)$ & $1.95(1.12)$ & NS \\
\hline & $\mathrm{V}$ & $4.23^{\star}$ & $1.40(1.91)$ & NS & 0.06 & $(1.28)$ & $0.77(1.17)$ & NS & $(1.31)$ & $1.02(1.01)$ & NS \\
\hline \multirow{3}{*}{31.5} & II & $(2.02)$ & $2.64(2.66)$ & NS & 3.33 & $(1.09)$ & $0.41(1.47)$ & NS & (1.36) & $1.30(1.36)$ & NS \\
\hline & III & $3.21^{\star}$ & $2.06(0.64)$ & NS & $4.31^{\star \star}$ & $(1.60)$ & $0.42(2.09)$ & NS & $3.72^{\star \star \star}(1.04)$ & $0.89(1.29)$ & NS \\
\hline & $\mathrm{V}$ & $4.73^{\star \star}(1.83)$ & $1.53(0.82)$ & NS & 2.24 & $(1.69)$ & $1.58(1.56)$ & NS & $3.57^{\star \star \star}(1.26)$ & $1.56(0.98)$ & NS \\
\hline \multirow[t]{3}{*}{125} & II & $4.82^{\star \star}(2.18)$ & $1.14(1.16)$ & NS & $5.59^{\star \star \star}$ & $(1.16)$ & $0.95(1.17)$ & $<0.02$ & $5.18^{\star \star \star}(1.26)$ & $1.03(0.83)$ & $<0.02$ \\
\hline & III & $1.95 \quad(2.15)$ & $2.29(1.51)$ & NS & $5.95^{\star \star \star}$ & $(1.98)$ & $1.14(1.41)$ & $<0.05$ & $3.81^{\star \star}(1.49)$ & $1.60(1.03)$ & NS \\
\hline & V & $6.86^{\star \star \star}(2.70)$ & $1.13(0.73)$ & $<0.05$ & $3.26^{\star \star}$ & (1.27) & $0.47(1.62)$ & NS & $5.18^{\star \star \star}(1.57)$ & $0.74(1.00)$ & $<0.01$ \\
\hline
\end{tabular}

${ }^{\star} \mathrm{P}<0.05 ;{ }^{\star \star} \mathrm{P}<0.02 ;{ }^{\star \star \star} \mathrm{P}<0.01 ;$ ANCOVA for paired samples (covariates: age and alcohol consumption). $\dagger \mathrm{P}$ values are of the $F$ test of ANCOVA for independent samples. Values are mean (SEM) differences between before and after the shift measures (dB).

restricted to the workers with sensorineural stages 2 and 3 versus the controls.

In the workers exposed to vibration the changes in vibrotactile perception thresholds at $16,31.5$, and $125 \mathrm{~Hz}$ were positively related to the estimated dose of vibration received over a workshift $(P<0.01)$. As an example, figure 3 displays the scatterplot and the fitted regression line for the relation between the changes in vibrotactile perception thresholds at $31.5 \mathrm{~Hz}$ for the third finger and the estimated dose of vibration. The fitted model suggests

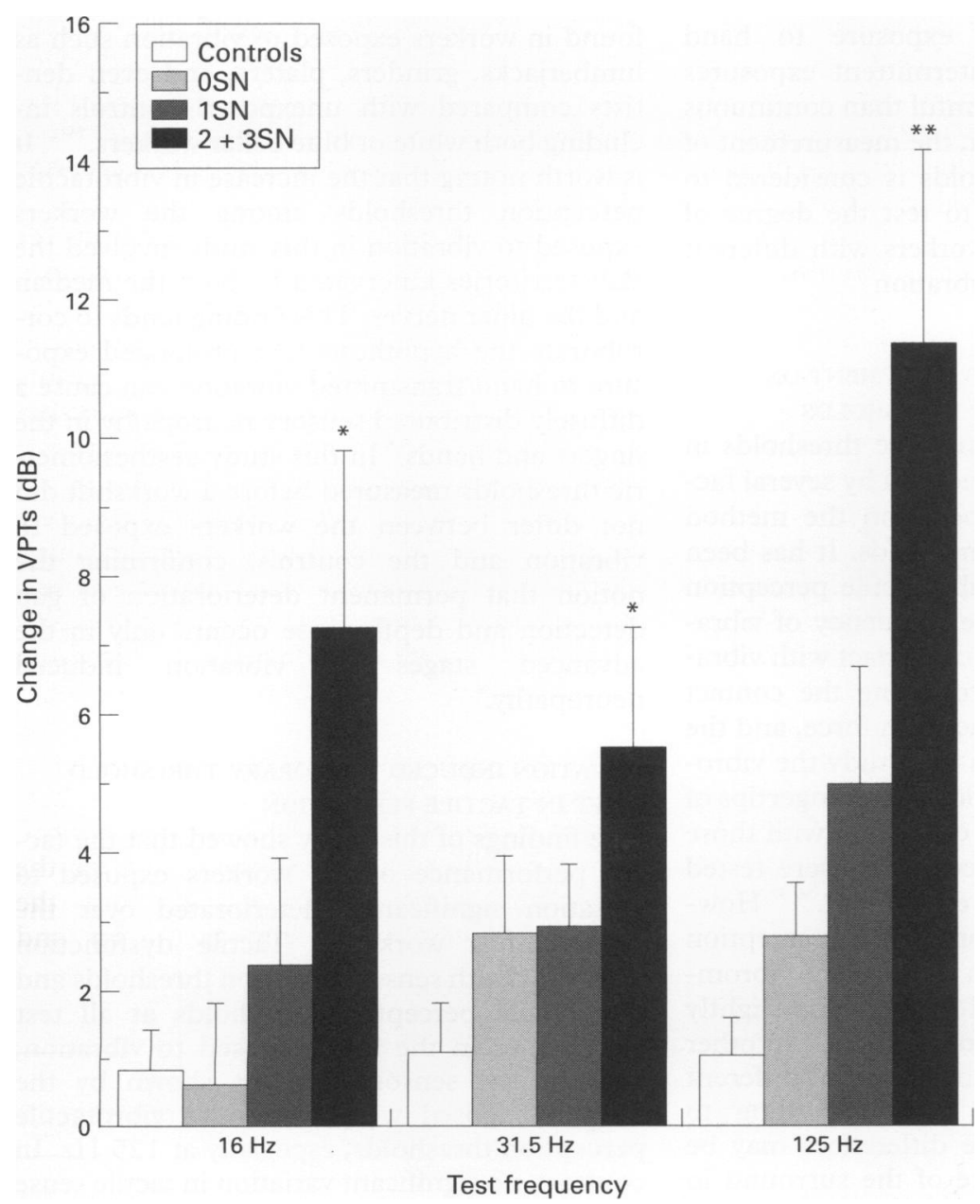

Figure 2 Changes over one workshift in vibrotactile perception thresholds at the frequencies of $16,31.5$, and $125 \mathrm{~Hz}$ in the fingers of the dominant hand of the workers exposed to vibration classified according to the sensorineural stages of the Stockholm workshop scale ( $0=48$ fingers, $1=30$ fingers, $2+3=12$ fingers). Histograms represent age and alcohol adjusted mean differences (bars=SEMs) between values before and after the shift (dB). Analysis of covariance (covariates: age and alcohol consumption)

shift $(d B)$. Analysis of that, on average, the expected change in vibrotactile perception threshold at $31.5 \mathrm{~Hz}$ was about $0.4 \mathrm{~dB}$ for a unit change in vibration dose expressed in $\mathrm{m}^{2} \mathrm{~s}^{-4} \mathrm{~h}$. No significant relation was found between aesthesiometric threshold changes and the estimated dose of vibration.

Stepwise multiple regression was used to examine the influence of age, alcohol consumption, vibration dose, and number of work cycles per day (the estimated number of fastening operations during a shift) on the changes over a workshift in vibrotactile perception thresholds. The number of work cycles per day was taken as an indicator of exposure to repetitive work. Vibration dose was found to be the only variable with a significant effect on the changes in vibrotactile perception thresholds $(\mathrm{P}<0.05)$. Regression analysis showed that vibration dose was correlated with repetitiveness $(\mathrm{P}<0.01)$. However, when vibration dose was removed from the regression equation the variable associated with repetitive movements at work was not found to be related to the changes in vibrotactile perception thresholds $(\mathrm{P}=0.24)$.

\section{Discussion}

In this study of changes induced by vibrations the tactile function of fingertips, aesthesiometric and vibrotactile thresholds were used to test separately the activity of three cutaneous mechanoreceptive units-namely, the FAI, FAII, and SAI receptor units. ${ }^{4-632-35}$ The measurement of fingertip tactile perception thresholds is considered a valuable tool for objective early detection of sensorineural disorders induced by vibration as an impairment to tactile sensitivity in the fingers may be the first sign of an incipient hand-arm vibration syndrome. $^{816}$ The assessment of the neural activity of skin mechanoreceptors and their associated nerve fibres is also of great interest for investigating the pathophysiological mechanisms underlying the neurological disorders affecting the fingers and hands of workers exposed to vibration as there is clinical and epidemiological evidence that vibration induced neuropathy can develop independently of the vascular and musculoskeletal components of the hand-arm vibration syndrome. ${ }^{22}$ Moreover, symptoms of peripheral sensorineural disorders may differ in occurrence and severity depending on the exposure to vibration. For 


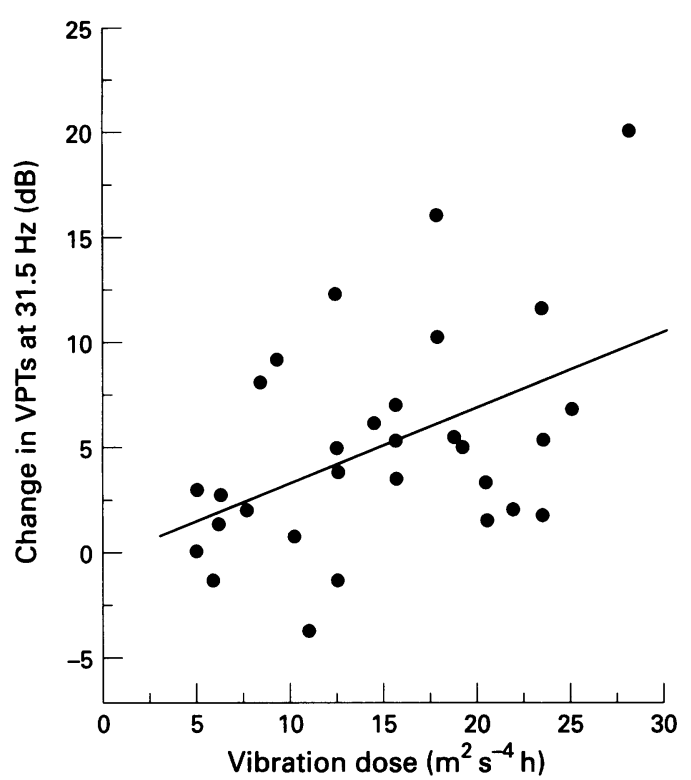

Figure 3 Change over one workshift in vibrotactile perception thresholds at the frequency of $31.5 \mathrm{~Hz}$ in the third finger of the dominant hand of the workers exposed to vibration $(n=30)$ as a function of the estimated daily vibration dose. Vibrotactile perception thresholds are expressed as the difference between measurements before and after the shift $(d B) \cdot y=-1.15+0.42 \cdot(x)(r=0.48$, $P<0.01$ ).

the same duration of exposure to hand transmitted vibration, intermittent exposures are thought to be less harmful than continuous exposures. In this context, the measurement of tactile perception thresholds is considered to be a promising method to test the degree of sensory dysfunction in workers with different patterns of exposure to vibration. ${ }^{15} 1934$

EFFECT OF THE MEASURING EQUIPMENT ON VIBROTACTILE PERCEPTION THRESHOLDS

It is known that vibration sense thresholds in the fingertips may be influenced by several factors, some of which depend on the method used to determine the thresholds. It has been reported that fingertip vibrotactile perception thresholds depend on the frequency of vibration stimulation, the area of contact with vibration, the conditions surrounding the contact area, the contact force, the push force, and the finger temperature. ${ }^{13}{ }^{17}$ In this study the vibrotactile perception thresholds in the fingertips of the control workers were consistent with those obtained in healthy subjects who were tested with the same measuring equipment. ${ }^{36}$ However, the fingertip vibrotactile perception thresholds measured with the present vibrometer were lower at 16 and $31.5 \mathrm{~Hz}$ and slightly higher at $125 \mathrm{~Hz}$ than those obtained in other groups of normal people by means of different measuring equipment. ${ }^{16203738}$ According to Maeda and Griffin, these differences may be explained by the presence of the surround in the vibrometer used in this study. ${ }^{37}$ The same authors found a lower variability and a greater repeatibility for vibrotactile perception thresholds determined with a measuring method which controls push force, contact force, and surround. $^{37}$
VIBRATION INDUCED SYMPTOMS AND SIGNS OF SENSORY NEUROPATHY

In this study sensorineural disorders were found in almost half of the workers exposed to vibration. However, the reported sensory disturbances in the fingers and hands were mild and only four workers (13.3\%) showed clinical abnormalities at the neurological examination. The prevalence of VWF was low $(3.3 \%)$ and comparable with that of the general population. These findings may be ascribed to the combined effect of several factors linked to the exposure conditions of this group of exposed operators-such as the short working period with vibrating tools (mean $2.5 \mathrm{y}$ ), the relatively low daily exposure to vibration (mean $\left(a_{h w}\right)_{e q(8)}=1.3 \mathrm{~ms}^{-2} \mathrm{rms}$ ), and the intermittency of tool usage. In spite of the scarcity of substantial pathological findings at the traditional neurological examination, after adjustment for potential confounders vibrotactile perception thresholds before exposure at all test frequencies were found to be greater in the men and women exposed to vibration than in the respective controls, the difference being significant mainly for the men. This finding is consistent with the results reported in several clinical and epidemiological studies in which significant increases in vibrotactile perception thresholds at various test frequencies were found in workers exposed to vibration such as lumberjacks, grinders, platers, and even dentists compared with unexposed controls including both white or blue collar workers. ${ }^{15-20} \mathrm{It}$ is worth noting that the increase in vibrotactile perception thresholds among the workers exposed to vibration in this study involved the skin territories innervated by both the median and the ulnar nerves. This finding tends to corroborate the hypothesis that prolonged exposure to hand transmitted vibration can cause a diffusely distributed sensory neuropathy in the fingers and hands. ${ }^{3}$ In this study aesthesiometric thresholds measured before a workshift did not differ between the workers exposed to vibration and the controls, confirming the notion that permanent deterioration of gap detection and depth sense occurs only in the advanced stages of vibration induced neuropathy. ${ }^{8}$

\section{VIBRATION INDUCED TEMPORARY THRESHOLD} SHIFT IN TACTILE PERCEPTION

The findings of this study showed that the tactile performance of the workers exposed to vibration significantly deteriorated over the course of a workshift. Tactile dysfunction involved depth sense perception thresholds and vibrotactile perception thresholds at all test frequencies in the men exposed to vibration, whereas the sensory changes shown by the women exposed were limited to vibrotactile perception thresholds, especially at $125 \mathrm{~Hz}$. In contrast, no significant variation in tactile sense was found in the control manual workers. Within the group exposed to vibration the acute changes in vibrotactile perception thresholds were found to be associated with the vibration dose received during the working day. After controlling for several confounders by 
multiple regression analysis, there was again evidence of a significant effect of vibration dose on the temporary threshold shift of vibration perception.

In this study the measurement of temporary threshold shift at various test frequencies was found to separate on a group basis the workers exposed to vibration with and without sensorineural symptoms from the control manual workers. Similar findings were reported by Lidström et al who measured the temporary threshold shift of vibrotactile sense at $100 \mathrm{~Hz}$ after vibration stimulation in a group of workers who used different types of rotary and percussive tools. ${ }^{11}$ In the present study the greater temporary threshold shift in vibrotactile perception found in the workers exposed to vibration with no symptoms compared with the controls may also suggest that the asymptomatic workers were affected with an initial, subclinical, form of vibration induced neuropathy. This seems to support the view that the measurement of temporary threshold shift in sense of vibration can contribute to diagnosis of early sensory changes in the fingers of subjects exposed to vibration even at an asymptomatic stage. ${ }^{11}$

COMPARISONS WITH OTHER EXPERIMENTAL AND FIELD STUDIES

Various experimental studies have investigated acute changes in vibrotactile perception thresholds induced by vibration under controlled laboratory conditions in either healthy subjects or workers exposed to vibration with or without symptoms. ${ }^{79-14}$ On studying 10 normal people exposed for five minutes to vibration with frequencies of 50 to $1200 \mathrm{~Hz}$ and a constant acceleration of $100 \mathrm{~ms}^{-2}$, Bjerker et al found a significant increase in vibrotactile perception thresholds for almost all test frequencies $(50-800 \mathrm{~Hz})$ with the greatest effect at 400 and $800 \mathrm{~Hz}$, irrespective of the stimulating frequency. ${ }^{9}$ Nishiyama and Watanabe found that the largest temporary threshold shift at $125 \mathrm{~Hz}$ in six male students occurred after 10 minutes of stimulation with a vibration frequency of $250 \mathrm{~Hz}$ delivered by a vibrating handle clasped with $5 \%$ or $10 \%$ of the maximum grip force. ${ }^{10}$ In general, laboratory investigations have pointed out a dependence of temporary threshold shift at various test frequencies on the magnitude and frequency of the vibration stimuli as well as on the duration of exposure and the grip strength. ${ }^{11}{ }^{13} 39$ A beneficial effect of rest periods during exposure to vibration has also been reported in a Japanese study of temporary threshold shift in eight male subjects. ${ }^{39}$ It was found that the longer the rest period between repeated vibration of $10 \mathrm{~ms}^{-2}$ at $31.5 \mathrm{~Hz}$, the smaller the temporary threshold shift at $63 \mathrm{~Hz}$ and the faster the recovery to the baseline values of vibrotactile perception thresholds. The magnitude of temporary threshold shift reported in those investigations was greater than that found in the present field study. This is likely to be due to differences in the exposure conditions and the time interval between threshold measurement and the end of exposure to vibration. Experimental studies of temporary threshold shift in the laboratory involve the use of sinusoidal vibration with intense acceleration levels and the measurement of temporary threshold shift is performed immediately after the end of exposure to vibration. The aim of this study was to investigate the changes in tactile perception provoked by actual use of hand held vibrating tools in the workplace. This means that the influence of some variables such as the physical characteristics of vibration, the operator's method of working, and the grip force exerted on the tool handle could not be controlled. Moreover, the temporary threshold shift of vibration perception was measured within five minutes of the end of a workshift so that the magnitude of the immediate temporary threshold shift after vibration could not be determined. However, it is remarkable that the results of this field study are not inconsistent with the experimental findings of a significant increase in vibrotactile perception thresholds with increasing exposure to vibration. It is also worth noting that overall the greatest changes in fingertip vibrotactile perception thresholds were found at the test frequency of $125 \mathrm{~Hz}$, a finding which may be associated with the high frequency spectra of the impact wrenches used by the workers exposed to vibration. This finding is also in agreement with the clinical evidence that the early stages of vibration induced neuropathy are primarily correlated with an impairment of the sensitivity of FAII receptor units which are anatomically connected to Pacinian corpuscles and are sensitive at frequencies above $40-50 \mathrm{~Hz}^{34}{ }^{35}$ Furthermore, in this study the temporary rise in vibrotactile perception thresholds at $125 \mathrm{~Hz}$, and partially at 16 and $31.5 \mathrm{~Hz}$, was associated with the severity of sensorineural disorders, confirming the results of other investigations which indicate a major involvement of FAII units, and to a lesser extent of FAI units, in the pathophysiological mechanisms underlying vibration induced neuropathy. ${ }^{11} 131618$

There are few studies of the acute changes in tactile perception caused by vibrating tools under actual operating conditions. ${ }^{121} 4041$ On investigating a group of hard rock miners by aesthesiometry, Haines et al found that over a workshift there was a significant effect of exposure to jackleg drills on the increase in the two point discrimination and depth sense perception thresholds of the fingertips of the dominant hand. ${ }^{21}$ Verberk et al investigated the changes in vibratory and tactile sense in the fingers of 24 volunteers who used sanders for 80 minutes in a laboratory setting. ${ }^{14}$ They found a significant increase in the two point discrimination thresholds of the right hand, whereas no changes occurred for both depth sense perception thresholds and vibration perception at the frequency of $100 \mathrm{~Hz}$. The frequency weighted accelerations of the sanders $\left(1.0-1.2 \mathrm{~ms}^{-2}\right)$ were lower than those measured on the impact wrenches of this study $\left(4.2-7.1 \mathrm{~ms}^{-2}\right)$ and this may, at least partially, account for the differences in the outcome of quantitative sensory testing between the two studies. Cadariu et al reported a significant 
increase in the temporary threshold shift of vibratory sensation in 17 operators after a working day with different types of percussive tools. ${ }^{40}$ The greatest reduction in the vibration sensitivity at the frequencies of 35 to $500 \mathrm{~Hz}$ was found in the subjects with more intense exposure to vibration. A complete recovery of temporary threshold shift occurred within 30 minutes of the end of the working day, independently of the intensity of exposure to vibration. In a group of workers who used grinding and polishing tools, Radzyukevich found that the magnitude of vibrotactile perception thresholds increased with the increase in the duration of employment. ${ }^{41}$ Moreover, the Russian author found that the permanent threshold shift in vibration sense was inversely related to the temporary threshold shift measured at the end of a working day. This is consistent with the findings of this study in which similar inverse relations between permanent and temporary threshold shifts were noticed for both aesthesiometric and vibrotactile thresholds. The relation between the permanent and temporary threshold shifts of tactile sense produced by exposure to vibration is not yet fully known, even though it has been reported that the mean temporary threshold shift in a group of workers exposed to hand transmitted vibration corresponded to the permanent shift in vibration perception that was found in the same group after 10 years of exposure. ${ }^{42}$ The analogy with the theory which claims an association between noise induced permanent and temporary threshold shift in hearing thresholds is evident but further longitudinal data are needed to support such a hypothesis.

\section{PATHOGENIC MECHANISMS}

The pathogenic mechanisms of the tactile sensory dysfunction caused by hand transmitted vibration are not yet fully clarified. The temporary threshold shift of tactile sense is thought to be the result of a depression of the excitability of the skin mechanoreceptive units secondary to intense vibration stimulation. ${ }^{7}$ The decreased sensitivity of the skin mechanoreceptors is transitory and seems to correspond to a phase of hyperpolarisation which follows rapid neural discharges from the receptors in response to local mechanical stress. It has been suggested that vibration induced changes in skin microcirculation and biomechanical properties of the skin may also contribute to the magnitude of temporary threshold shift after exposure to vibration. ${ }^{7}$ Other pathogenic mechanisms for the nerve injury caused by segmental vibration have been suggested by the findings of histological studies of both experimental animals and human finger skin biopsies. ${ }^{43-46}$ It has been reported that acute exposure to vibration induced epineural oedema in the sciatic nerve of rats, resulting in an increased intraneural pressure which can interfere with nerve fibre nutrition..$^{43}$ Moreover, prolonged exposure to intense vibration was found to provoke a variety of lesions in the peripheral nerves of rabbits and rats-such as disruption of the myelin sheaths, constriction of the axons, and disappearance of microtubules and microfilaments in the axons. ${ }^{45} 46$ These findings are consistent with the results of finger skin biopsy studies performed by Takeuchi et al who found severe loss of myelin sheath, perineural fibrosis, and a decreased number of myelinated nerve fibres in the fingers of 30 patients exposed to hand transmitted vibration. ${ }^{44}$ The perineural fibrosis was interpreted as the result of previous vibration induced oedema. It is noteworthy that the main morphological changes found in the experimental animals occurred in the nerve fibres with diameter from 2 to $12 \mu \mathrm{m}$-that is, sensory fibres from Pacinian and Meissner corpuscles and other neural endings sensitive to pressure, touch, and pain. ${ }^{45}$ Thus, the overall results of clinical and experimental studies seem to suggest a plausible link between subjective symptoms, psychophysical changes, and pathoanatomical lesions in vibration induced neuropathy.

\section{EXPOSURE-RESPONSE RELATION}

In this study of users of impact wrenches the estimated daily exposure to vibration, expressed in terms of $\left(a_{h w}\right)_{e q(8)}$, was slightly greater than $1 \mathrm{~ms}^{-2}$, an energy equivalent acceleration value that is considered by some researchers as the threshold level below which exposure to vibration should not cause notable adverse effects on health and safety of workers. ${ }^{47}{ }^{48}$ This threshold value is also consistent with the dose-effect relations included in the annexes to the standards ISO 5349 and BS $6842 .{ }^{28}{ }^{31}$ However, it should be noted that the risk prediction in the ISO and BS standards applies to vibration induced vascular disorders (VWF), whereas at present there are insufficient exposure and epidemiological data to establish that the current exposure-response relation is also valid for vibration induced neurological disturbances. The findings of a study of the dose-response relation for sensory neuropathy among platers and assemblers suggested that at a low rate of prevalence (around 10\%) sensorineural symptoms seemed to appear earlier than those related to vascular disorders. ${ }^{49}$ In the same study the prevalence of sensorineural disorders tended to increase with the increase of vibration dose, but no reliable doseresponse relation could be established. The present study showed that working operations with impact wrenches can cause a deterioration of tactile function which was found to be related to the vibration dose accumulated over a workshift. However, to date the available epidemiological data are insufficient to outline the form of a possible dose-response relation for vibration induced sensorineural disorders.

\section{Conclusion}

The findings of this study indicate that intermittent exposure to hand transmitted vibration can provoke acute tactile dysfunction in users of impact wrenches with mild sensory symptoms and minor neurological abnormalities. It is thought that sensorineural disorders may cause more work disability than VWF as their persistence can lead to incapacity to 
perform tasks requiring manipulative skill. The loss of tactile sense can also disturb the manual control of power tools increasing the risk of accidents at the workplace. It is a matter of concern for the occupational health physician that objective signs of acute tactile dysfunction could be detected in workers exposed to an energy equivalent acceleration at a level that is considered to be associated with a minimal risk for vibration induced adverse health effects. $^{28} 314748$ These considerations call for the implementation of programmes of technical measures and medical surveillance aimed at preventing the progression of neurological disorders in the surveyed worker group.

1 Bovenzi M. Medical aspects of the hand-arm vibration syndrome. International fournal of Industrial Ergonomics 1990;6:61-73.

2 Griffin MJ. Handbook of human vibration. London: Academic Press, 1990.

3 Gemne G, Lundström R, Hansson JE. Disorders induced by work with hand-held vibrating tools. Solna: National Institute of Occupational Health, Arbete och Hälsa 1993:6.

4 Lundström R. Responses of mechanoreceptive afferent units in glabrous skin of the human hand to vibration. Scand 7 Work Environ Health 1986;12:413-6.

5 Johansson RS, Lundström U, Lundström R. Responses of mechanoreceptive afferent units in the glabrous skin of the human hand to sinusoidal skin displacement. Brain Res 1982;244:17-25.

6 Vallbo ÅB, Johansson RS. Properties of cutaneous mechanoreceptors in the human hand related to touch sensation. anoreceptors in the human han
Human Neurobiol 1984;3:3-14.

7 Lundström R, Johansson RS. Acute impairment of the sensitivity of skin mechanoreceptive units caused by vibration exposure of the hand. Ergonomics 1986;29:687-98

8 Anonymous. Clinical and laboratory diagnostics of neurological disturbances in workers using hand-held vibrating tools. Report from discussions in a working group. In: Gemne G, Brammer AJ, Hagberg M, Lundström $\mathrm{R}$, Nilsson T, eds. Proceedings of the Stockholm Workshop 94. Hand-arm vibration symdrome: diagnostics and quantitative relationships to exposure. Solna: National Institute of Occupational Health, Arbete och Hälsa 1995;5:187-94.

9 Bjerker N, Kylin B, Lidström IM. Changes in the vibratory sensation threshold after exposure to powerful vibration. Ergonomics 1972;15:399-406.

10 Nishiyama K, Watanabe S. Temporary threshold shift of vibratory sensation after clasping a vibrating handle. In Arch Occup Environ Health 1981;49:21-33.

11 Lidström IM, Hagelthorn G, Bjerker N. Vibration perception in persons not previously exposed to local vibration and in vibration exposed workers. In: Brammer AJ, Taylor $\mathrm{W}$, eds. Vibration effects on the hand and arm in industry. New York: John Wiley, 1982:59-65.

12 Verberk MM, Sallé HJA, Kempers O. Vibratory and tactile sense of the fingers after working with sanders. Int Arch Occup Environ Health 1985;56:217-23.

13 Harada N, Griffin MJ. Factors influencing vibration sense thresholds used to assess occupational exposure to thresholds used to assess occupational exposure to

14 Maeda S, Griffin MJ. Temporary threshold shifts in fingertip vibratory sensation from hand-transmitted vibration and repetitive shock. $B r \mathcal{F}$ Ind Med 1993;50:360-7.

15 Brammer AJ, Taylor W, Piercy JE. Assessing the severity of the neurological component of the hand-arm vibration syndrome. Scand $\mathcal{f}$ Work Environ Health 1986;12:428-31.

16 Lundström R. Digital tactilogram as a diagnostic tool for early diagnosis of vibration induced neuropathy. In: Okada A, Taylor W, Dupuis $\mathrm{H}$, eds. Hand-arm vibration. Kanasawa: Kyoei Press, 1989:75-7.

17 Hayward RA, Griffin MJ. Measures of vibrotactile sensitivity in persons exposed to hand-arm vibration. Scand $\mathcal{F}$ Work ity in persons exposed to hand-
Environ Health 1986;12:423-7.

18 Virokannas $H$. Vibration perception thresholds in workers exposed to vibration. Int Arch Occup Environ Health 1992; 64:377-82

19 Virokannas $H$. Dose-response relation between exposure to two types of hand-arm vibration and sensorineural perception of vibration. Occup Environ Med 1995;52:332-6.

20 Åkesson I, Lundborg G, Horstmann V, Skerfving S. Neuropathy in female personnel exposed to high frequency vibration. Occup Environ Med 1995;52:116-23.

21 Haines T, Chong J, Verrall AB, Julian J, Bernholz C, Spears R, Muir DCF. Aesthesiometric threshold changes over the course of a workshift in miners exposed to hand-arm vibration. Br f Ind Med 1988;45:106-11.

22 Brammer AJ, Taylor W, Lundborg G. Sensorineural stages of the hand-arm vibration syndrome. Scand $\mathcal{f}$ Work Environ Health 1987;13:279-83.
23 Carlson WS, Samueloff S, Taylor W, Wasserman DE. Instrumentation for measurement of sensory loss in fingertips. $\mathcal{F}$ Occup Med 1979;21:260-4.

24 Bovenzi M, Zadini A. Quantitative estimation of aesthesiometric thresholds for assessing impaired sensation in workers exposed to vibration. Int Arch Occup Environ Health ers exposed to

25 HVLab tactile vibrometer. HVLab tactile vibrometer user guide, V1. Southampton: Institute of Sound and Vibration Research, University of Southampton, 1991:HTV9101.

26 British Standard Institution. British standard specification for pure tone air conduction threshold audiometry for hearing conservation purposes. London: BSI, 1986:6655.

27 International Organization for Standardization. Acousticspure tone air conduction threshold audiometry for hearing conservation purposes. Geneva: ISO, 1983:6189.

28 International Organization for Standardization. Mechanical vibration-guidelines for the measurement and the assessment of human exposure to hand-transmitted vibration. Geneva: ISO, human exposur

29 International Organization for Standardization. Hand-held portable power tools: measurement of vibrations at the handle.Part 1: general. Geneva: ISO, 1988:8662-1.

30 Jorulf L. Vibration-induced effects caused by impact wrenches used in truck assembley. Scand $\mathcal{f}$ Work Environ Health 1986;12:269-71.

31 British Standard Institution. Measurement and evaluation of human exposure to vibration transmitted to the hand. London: BSI, 1987:6842.

32 Johnson KO, Phillips JR. Tactile spatial resolution. I Two-point discrimination, gap detection, grating resoluTwo-point discrimination, gap detection, grating resolu-
tion, and letter recognition. $\mathcal{F}$ Neurophysiol 1981;46:1177tion,

33 Phillips JR, Johnson KO. Tactile resolution. II. Neural representation of bars, edges, and gratings in monkey primary afferents. $\mathcal{F}$ Neurophysiol 1981;46:1192-203.

34 Brammer AJ, Piercy JE, Auger PL, Nohara S. Tactile perception in hands occupationally exposed to vibration. $\mathcal{F}$ Hand Surg 1987;12:870-5.

35 Pyykkö I, Brammer AJ, Starck J, Färkkilä M. Vibrationinduced neuropathy. In: Okada A, Taylor W, Dupuis $\mathrm{H}_{\text {, }}$ eds. Hand-arm vibration. Kanasawa: Kyoei Press, 1989: 93-6.

36 Hadlington $\mathrm{AB}$, Griffin $\mathrm{MJ}$. Vibrotactile sensitivity and finger systolic blood pressure in workers exposed to hand-transmitted vibration. In: Dupuis $H$, Christ $E$, Sandover DJ, Taylor W, Okada A, eds. Proceedings of the 6th International Conference on Hand-Arm Vibration. Sankt Augustin:Hauptverbandes-der-gewerblichen-Berufsgenossenschaften, 1992:845-52.

37 Maeda S, Griffin MJ. A comparison of vibrotactile thresholds on the finger obtained with different equipment. Ergonomics 1994;37:1391-406.

38 Lundström R, Strömberg T, Lundborg G. Vibrotactile perception threshold measurements for diagnosis of sensory neuropathy. Int Arch Occup Environ Health 1992;64:201-7.

39 Youropava Y, Kanada K. Temporal threshold shift of hand vibratory sensation. In: Okada A, Taylor W, Dupuis H, eds.
Hand-arm vibration. Kanasawa: Kyoei Press Co, 1989:15760.

40 Cadariu GH, Gradina C, Constantinidis A, Marinesco V. Modifications des reactions de l'organisme chez les ouvrier exposes aux vibrations et au bruit a caracteristiques physiques diferentes. XVieme Congres International du Medicine du Travail, $A I V-56$. Wien: 1966:209-12.

41 Radzyukevich TM. Interrelation of temporary and permanent shifts of vibration and pain sensitivity threshold under the effect of local vibration. Gigiena Truda $i$ Professional'mye Zabolevaniya 1969;14:20-3.

42 Malinskaya NN, Filin AP, Shkarinov LN. Problem of occupational hygiene in operating mechanised tools. Vestnik pational hygiene in operating mechanised
Akademii Meditsinkikh USSR 1964;19:31-6.

43 Lundborg G, Dahlin LB, Hansson HA, Pyykkö I. Intraneural edema following exposure to vibration. Scand $₹$ Work Environ Health 1987;13:326-9.

44 Takeuchi T, Takeya M, Imanishi $H$. Pathological changes observed in the finger biopsy of patients with vibration-
induced white finger. Scand $f$ Work Environ Health 1986;12:280-3.

45 Ho ST, YU HS. Ultrastructural changes of the peripheral nerve induced by vibration: an experimental study. $B r f$ Ind Med 1989;46:157-64.

46 Chang KY, Ho ST, Yu HS. Vibration induced neurophysiological and electron microscopical changes in rat periphological and electron microscopical changes in

47 Miura T, Morioka M, Kimura K, Akutu A. On the occupational hazards by vibrating tools. Report 4. F Sci Labor 1959;35:760-7.

48 Brammer AJ. Threshold limit for hand-arm vibration exposure throughout the workday. In: Brammer AJ, Taylor W, eds. Vibration effects on the hand and arm in industry. New York: John Wiley, 1982:290-301.

49 Lundström $R$, Hagberg $M$, Nilsson T. Dose-response relationship for hand-arm vibration syndrome with respect to sensorineural disturbances among platers and assemblers. In: Dupuis H, Christ E, Sandover DJ, Taylor W, Okada A, eds. Proceedings of the 6th International Conference on Hand-Arm Vibration. Sankt Augustin: Hauptverbandesder-gewerblichen-Berufsgenossenschaften, 1992:865-74. 